\title{
COGNITIVE PROCESSES IN RESPONSE TO GOAL FAILURE: A STUDY OF RUMINATIVE THOUGHT AND ITS AFFECTIVE CONSEQUENCES
}

\author{
NEIL P. JONES \\ University of Pittsburgh School of Medicine \\ ALISON A. PAPADAKIS AND CAROLINE A. ORR
Loyola University Maryland
}

TIMOTHY J. STRAUMAN

Duke University

Failure to make progress toward personal goals can lead to negative affective states, such as depression and anxiety. Past research suggests that rumination in response to goal failure may prolong and intensify those acute emotional responses, but that process remains unclear. We examined ruminative thought processes following experimentally manipulated exposure to past failures to attain advancement (promotion) goals and safety (prevention) goals. We predicted that priming of past promotion and prevention goal failures would lead individuals to think repetitively about these failures and that negative affect would be evoked by their recognition of their failures. Further, we predicted that when people experience a sufficient magnitude of negative affect, ruminative thought would intensify and prolong the negative affect associated with that type of goal failure. Results yielded strong support for our predictions regarding promotion goal failure and modest support for those regarding prevention goal failure.

Supported by the Duke Interdisciplinary Initiative in Social Psychology, the Duke University Graduate School Summer Research Fellowship, and by the National Institute of Mental Health grant MH-086811.

Address correspondence to N. P. Jones, Western Psychiatric Institute and Clinic, University of Pittsburgh, Pittsburgh Pennsylvania, 3811 O'Hara Street, Pittsburgh PA 15213; E-mail: jonesnp@upmc.edu. 
Individuals constantly pursue personal goals such as career goals, relationship goals, or personal traits (e.g., being helpful; Shah, 2005). While failure to achieve or make progress toward goals results in normative acute negative affect (e.g., Moberly \& Watkins, 2010), chronic failure to achieve or make progress toward goals is associated with continued distress and the development and maintenance of mood and anxiety disorders (Strauman, 2002). However, the mechanisms by which the acute distress following goal failure leads to the chronic distress found in mood and anxiety disorders are unclear (Strauman, Costanzo, Jones, McLean, \& Eddington, 2007). In this study, we explore how rumination following the cognitive activation of goal failure may play a role in prolonging and intensifying negative affect.

Self-regulation theories suggest how progress toward different types of goals can result in different acute affective states (Carver \& Scheier, 1998; Higgins, 1997). Regulatory focus theory (Higgins, 1997) postulates that individuals have basic needs for advancement and growth as well as for safety and security. Individuals fulfill their needs for advancement and growth by pursuing and attaining promotion goals (i.e., ideals, hopes, and aspirations) and their needs for safety and security by pursuing and attaining prevention goals (i.e., oughts, duties, or obligations). While perceived failure to attain promotion goals generates dysphoric emotions, perceived failure to attain prevention goals generates anxious emotions (e.g., Hardin \& Lakin, 2009).

Although self-regulation theories account for acute affective states following goal failure, they do not explain how those acute states can become chronic negative affect. We and others have proposed rumination as a possible mechanism (e.g., Segerstrom, Tsao, Alden, \& Craske, 2000; Strauman et al., 2007, pp. 859-861). Rumination is a multifaceted construct with differing subtypes and definitions in the literature (Siegle, Moore, \& Thase, 2004). Some subtypes (e.g., positive rumination) have positive outcomes (for a review, see Watkins, 2008) and may facilitate goal attainment by keeping goals salient (Martin \& Tesser, 2006), while other subtypes (e.g., depressive rumination, worry) have negative outcomes, such as depressive episodes (e.g., Abela \& Hankin, 2011). Some of the core elements of negative rumination subtypes are repetitiveness and intrusiveness (Ehring et al., 2011). In the current study, we define rumination as repetitive, intrusive thoughts with a negative focus, which includes 
depressive rumination, post-event rumination, and thoughts about the reasons for and implications of goal failure.

Goal failure may prompt rumination, particularly when individuals cannot reprioritize or disengage from the goal or identify alternate ways to attain the goal (Martin \& Tesser, 1996). Brunstein \& Gollwitzer (Study 1; Brunstein \& Gollwitzer, 1996) demonstrated that exposure to failure feedback on a task linked to professional goals results in rumination about that failure during a subsequent task. Also, in two diary studies failure to attain personal goals was associated with rumination (Lavallee \& Campbell, 1995; Moberly \& Watkins, 2010). However, those studies did not manipulate failure, examine different types of goal failure, or test if rumination intensifies negative affect over time.

Other research not focused on goal failure suggests that rumination can prolong and intensify negative affect. In several repeatedmeasures experiments researchers recruited individuals with a sad mood or induced a sad mood and then induced rumination or distraction (Thomsen, 2006). Those studies demonstrate that induced rumination is associated with sadness/depression (e.g., Nolen-Hoeksema \& Morrow, 1993). Similarly, there is an association between rumination and anxiety in several experiments that use the rumination-induction paradigm or a trait-stress paradigm, in which individuals with and without trait rumination are subjected to stress with the idea that high trait ruminators will ruminate in response to stress (e.g., Thomsen, Jørgensen, Mehlsen, \& Zachariae, 2004). Many of those studies are limited by a rumination-induction paradigm that instructs participants to engage in specific thought processes (e.g., think about the way you feel inside). Those instructions reflect the researchers' conception of rumination but not necessarily the participants' naturally produced rumination, which may function differently and have different outcomes. This suggests the need for additional research on naturally occurring rumination particularly about goal failure.

Correlational research in college students and adolescent girls suggests moderate to high levels of rumination exacerbate the effect of chronic promotion goal failure on depressive symptoms (Jones, Papadakis, Hogan, \& Strauman, 2009; Papadakis, Prince, Jones, \& Strauman, 2006). However, in those studies rumination was measured as a trait and not necessarily linked to goal failure. Further, we were unable to test if rumination predicted affective changes 
prospectively and if promotion and prevention goal failures were associated uniquely with depression and anxiety, respectively.

In order to address the limitations of previous research, we designed an experimental study in which we primed participants with their own promotion and prevention goal failure experiences. After priming them, we provided them an opportunity to ruminate naturally during a quiet period disguised as a meditation period, for which participants were given no meditation instructions. Although meditation is associated with decreased rumination among trained individuals (Jain et al., 2007), the meditation cover story was selected since young adults, who are largely novice or nonmeditators, often experience rumination during periods of silence despite meditation instructions (e.g., Feldman, Greeson, \& Senville, 2010).

This design allowed us to examine two main predictions. First, that exposure to promotion and prevention goal failure leads to state rumination and increased dejection or decreased quiescence, respectively, for individuals experiencing chronic goal failure. We examined quiescence rather than anxiety because state anxiety scales are not sensitive to changes in anxiety in nonclinical samples because those scales generally reflect somatic complaints which require higher arousal (Walter et al., 2007). Second, we tested the prediction that negative affect induced by exposure to goal failure leads to state rumination, which, in turn, intensifies and prolongs the induced negative affect. We controlled for other traits that might increase negative affect such as trait rumination (Trapnell \& Campbell, 1999) and pessimism (Hardin \& Leong, 2005) to isolate the effects of state rumination on negative affect.

\section{METHOD}

\section{PRELIMINARY ASSESSMENT}

The two-part study was presented to participants as two unrelated studies. Graduate and professional students were recruited to participate in a study of individual differences in motivation through flyers and electronic listserves. The sample of 93 students $(80 \%$ female; age: $M=26.33, S D=4.37$, Range $=21-48$; ethnicity: $72 \%$ Caucasian, 12\% Asian, 9\% African American) completed the study in private rooms. 


\section{PRELIMINARY MEASURES}

Rumination, Pessimism, and Mood Measures. We assessed trait rumination with the rumination scale from the Rumination/Reflection Questionnaire (RRQ; Trapnell \& Campbell, 1999), dispositional pessimism with the Extended Life Orientation Test (Chang, Maydeu-Olivares, \& D'Zurilla, 1997), and current depressive symptoms with the Beck Depression Inventory (BDI; Beck, Ward, Mendelson, Mock, \& Erbaugh, 1961).

Self-Regulatory Success/Failure Measure. The computerized Selves Questionnaire (CS; Jones et al., 2009) was used to assess chronic failure to attain promotion and prevention goals. Each participant generated adjectives representing his or her promotion and prevention goals. For promotion goals they listed "six adjectives that describe ... the attributes of the kind of person you wish or desire to be," and for prevention goals they listed "six adjectives that describe ... the attributes ... of the person you believe it is your duty or responsibility to be." Participants' attributes were presented back to them, and they were asked to rate their progress toward each attribute on a 7-point scale. Participants rated their discrepancy from each attribute on a 5-point scale in response to the question "how much do you think this attribute actually describes or applies to you at this time?" (Hardin \& Leong, 2005). We created composite measures of chronic promotion $(M=3.15, S D=.73, \alpha=.79)$ and prevention $(M=3.09, S D=.70, \alpha=.75)$ goal failure by averaging progress (reverse scored) and discrepancy responses.

\section{EXPERIMENTAL SESSIONS}

\section{Participants}

The second study sample was comprised of 78 participants from the first study. The subsample was $79 \%$ female (age: $M=26.37, S D$ $=4.56$, Range $=21-48$; ethnicity: $69 \%$ Caucasian, $13 \%$ Asian, 10\% African American) and did not differ from participants in only the first part on any preliminary measures (all $p s>.05$ ). On the BDI, $32 \%$ of participants scored in the mild or above range $(M=8.82, S D$ $=7.10$, Range: $0-38$ ). 


\section{Procedure}

Participants were told that the purpose of the second study was to examine their reflections as they wrote about themselves and engaged in meditation. Each participated in three counterbalanced sessions on three consecutive days, which were completed individually on a computer in a private room. Unknown to participants, each session included a priming of their own promotion or prevention goals or yoked-control goals from the preliminary assessment. In each session, participants completed a baseline measure of affect (T1); a 15-minute writing task, which varied by priming condition; and a post-writing measure of affect (T2). Immediately after participants had a quiet period in which they engaged in a five-minute meditation exercise then completed post measures of affect (T3) and a state rumination (T3).

Writing Task. In each condition (promotion failure, prevention failure, and yoked-control), participants completed a writing task. They wrote about situations when they failed to live up to three trait attributes selected for them individually, as described below. In the promotion and prevention conditions, participants wrote about a time in their lives when they "wished or aspired" (promotion condition) or "felt it was [their] duty or obligation" (prevention condition) "to be more [attribute], but [they] weren't." In the yoked-control condition, participants received a random combination of promotion and prevention prompts. The writing task was designed to prime participants' promotion and prevention failure experiences. Participants were instructed to write about attributes (e.g., intelligent, respectful, organized) selected from the participants' own promotion or prevention goals from the CS. Consistent with previous work (Strauman, 1992), we selected goals that the participants rated highest on goal failure and were semantically unrelated to the participant's prevention goals (in the promotion condition) or promotion goals (in the prevention condition). In the yoked-control condition, attributes were other participants' promotion and prevention goals and were semantically unrelated to the target participant's own goals. The yoked-control condition provided a test of the alternative hypothesis that the literal content of cues, rather than their status as motivationally significant personal goals, would influence rumination and affect. 
Quiet Period. After rating their post-writing affect, participants heard the following: "In this sitting practice we would like you to just sit with your eyes closed. The bell will ring three times to signal the beginning and the end of the exercise." They were not given any meditation instructions, and few subjects $(n=9)$ reported prior meditation training. The meditation period was designed to be a quiet period during which rumination could occur naturally.

\section{MEASURES}

Affect Scales. To decrease testing effects due to repeated and closely spaced assessments with the same measure, which is a serious threat to internal validity in repeated measurement (Shadish, Cook, \& Campbell, 2002), we generated multiple versions of measures for dejection and quiescence. There were three three-item versions $(\alpha s=.77, .72, .81)$ for dejection and two single item versions for quiescence. The items were drawn from the Sadness and Serenity subscales of Positive and Negative Affect Scale - Expanded Form (PANAS-X; Watson \& Clark, 1990). The versions were randomized within individuals across the three time points (T1, T2, and T3) to control for version and order effects. This strategy reduces the relative influence of trait affect on the measurement of state affect (Watson \& Clark, 1994) and is similar to the disaggregation of measures technique used in structural equation modeling when assessment is repeated over time (Landis, Beal, \& Tesluk, 2000). Participants rated all items, which were adjectives describing sadness (e.g., sad, downhearted) and quiescence (i.e., calm or relaxed) on a five-point scale from 1 (felt very slightly or not at all) to 5 (felt very much).

Emotional Content of the Writing Task. We analyzed participants' writing task data for emotion with the text analysis program, Linguistic Inquiry and Word Count (LIWC2001; Pennebaker, Francis, \& Booth, 2001). Levels of sadness, anxiety, and anger were used to see if the manipulation was effective in eliciting the type of affect predicted for each condition.

State Rumination Scale. We developed a measure of state rumination to assess the repetitive, intrusive, and negative quality of participants' thoughts. It included items adapted from the Response Styles Questionnaire (RSQ; Nolen-Hoeksema \& Morrow, 1991), the White Bear Suppression Inventory (WBSI; Wegner \& Zanakos, 
1994), and the RRQ (Trapnell \& Campbell, 1999). Sample items include "I thought about things I'd prefer not to think about" (WBSI) and "I found myself reevaluating something I'd done" (RRQ). Participants checked off descriptions that matched their thoughts during the quiet period. There were three eight-item versions of the scale (Kuder-Richardson Formula $20=.32, .58, .64$ ), counterbalanced to control for version effects. Because one version had poor internal consistency, we dropped that version from the analyses involving state rumination, resulting in state rumination data on 52 participants in the promotion, 54 in the prevention, and 50 in the yoked-control conditions. Analyses were also conducted with the full sample resulting in results consistent with those presented here.

\section{RESULTS}

\section{PRIMING MANIPULATION CHECK}

In the promotion condition, participants recalled failure situations associated with more sadness $(M=6.32, S E=1.08)$ relative to the prevention, $M=4.04, S E=0.80, t(77)=1.88, p=.032$ one-tailed, $d$ $=0.27$, and yoked-control, $M=4.26, S E=0.84, t(77)=1.79, p=.039$ one-tailed, $d=0.24$, conditions after controlling for level of anxiety and anger. In the prevention condition, participants recalled failure situations associated with similar in the level of anxiety $(M=4.99$, $S E=0.78)$ relative to the promotion $(M=6.77, S E=1.37)$ and yokedcontrol $(M=5.43, S E=0.93)$ conditions $(p s>.05)$ after controlling for level of sadness and anger. However, in the prevention condition, participants recalled failure situations associated with marginally more anger $(M=7.47, S E=1.26)$ relative to the promotion condition, $M=5.11, S E=0.96, t(77)=1.53, p=.065$ one-tailed, $d=$ 0.27 , and significantly more anger relative to the yoked-control condition, $M=4.94, S E=0.81, t(77)=1.80, p=.038$ one-tailed, $d=0.27$, after controlling for level of sadness and anxiety. In summary, while the promotion condition worked as predicted, the prevention condition differed from the other conditions in the recall of situations associated with anger and not anxiety; hence, this manipulation did not perform as intended. Given that increases in anger could potentially reduce experienced quiescence, we decided to proceed with examining changes in emotion in the prevention condition. 


\section{PREDICTIONS FROM REGULATORY FOCUS THEORY}

\section{Analytic Strategy}

Measures of chronic promotion and prevention failure are moderately to strongly correlated (e.g., $r=.46, p<.0001$, in the current study), as are measures of quiescence and dejection (see Table 1). Therefore, there are guidelines about how to detect specificity in the predicted associations between promotion/prevention failure and negative affect (see Boldero, Moretti, Bell, \& Francis, 2005). The guidelines specify it is necessary to control for both the alternate type of goal failure and emotion when examining the effect of type of goal failure of interest on the emotion of interest. Thus, we controlled for quiescence and prevention goal failure when examining the effect of chronic promotion failure on changes in dejection from T1 to T2. Similarly, we controlled for dejection and chronic promotion failure when examining changes in quiescence from T1 to T2.

\section{Changes in Dejection Following Exposure to Promotion Failure}

In the following analyses, we tested the prediction that exposure to cues for promotion goal failures would be uniquely associated with increases in dejection for individuals who described themselves on the CS as chronically failing to attain their promotion goals. We conducted a hierarchical general linear mixed model analysis using REML with an unstructured covariance structure to predict changes in dejection from $\mathrm{T} 1$ to $\mathrm{T} 2$ with priming condition and time as within-subject factors. Quiescence (pooled across T1 and T2) and chronic prevention failure were controlled for in step 1; main effects of chronic promotion failure, condition, and time were entered in step 2; and all possible two-way and the three-way interactions were entered in step 3.

After controlling for quiescence, $b=-0.21, S E=0.03, F(1,75)=$ 42.87, $p<.0001, \eta^{2}=.36$, and chronic prevention failure, $b=0.03$, $S E=0.10, F(1,75)=0.08, p=.772, \eta^{2}=.00$, which demonstrated the expected effects, the predicted chronic promotion failure $\times$ condition $\times$ time interaction in step 3 was statistically significant $F(2,75)$ $=3.43, p=.038, \eta^{2}=.08$ (see Table 2 ). The chronic promotion failure $\times$ condition $\times$ time interaction was probed at different levels of 
TABLE 1. Correlations Among Variables Used In Path Analyses

\begin{tabular}{|c|c|c|c|c|c|c|c|c|}
\hline & & 1 & 2 & 3 & 4 & 5 & 6 & 7 \\
\hline \multicolumn{9}{|c|}{ Promotion Condition Below Diagonal/Prevention Condition Above Diagonal } \\
\hline 1. & Trait Rumination & - & $.47^{* * *}$ & $.25+$ & -.20 & $.32^{*}$ & .18 & -.13 \\
\hline 2. & Pessimism & $.42^{* *}$ & - & $.39^{* *}$ & -.15 & .20 & $.23+$ & $-.42^{* *}$ \\
\hline 3. & T2-Dejection & .22 & $.34^{*}$ & - & $-.25 t$ & $.23+$ & $.69 * * *$ & $-.24+$ \\
\hline 4. & T2-Quiescence & $-.44^{* *}$ & -.22 & $-.31^{*}$ & - & $-.36^{* *}$ & -.16 & $.50^{* * *}$ \\
\hline 5. & State Rumination & $.26+$ & $.31^{*}$ & $.31^{*}$ & -.17 & - & .22 & $-.27^{*}$ \\
\hline 6. & T3-Dejection & $.24+$ & $.33^{*}$ & $.79^{* * *}$ & $-.26+$ & $.40^{* *}$ & - & $-.24+$ \\
\hline 7. & T3-Quiescence & $-.35^{* *}$ & $-.47^{* * *}$ & -.19 & $.42 *$ & $-.37^{* *}$ & $-.32 *$ & - \\
\hline \multicolumn{9}{|c|}{ Yoked-Control Condition } \\
\hline 1. & Trait Rumination & - & & & & & & \\
\hline 2. & Pessimism & $.42^{* *}$ & - & & & & & \\
\hline 3. & T2-Dejection & $.24+$ & -.07 & - & & & & \\
\hline 4. & T2-Quiescence & -.15 & -.04 & $-.36^{*}$ & - & & & \\
\hline 5. & State Rumination & $.31 *$ & .16 & $.26^{*}$ & -.21 & - & & \\
\hline 6. & T3-Dejection & .16 & -.02 & $.82^{* * *}$ & $-.35^{*}$ & $.27+$ & - & \\
\hline 7. & T3-Quiescence & -.25 & -.12 & -.15 & $.50^{* * *}$ & $-.28+$ & -.19 & - \\
\hline \multirow[t]{2}{*}{ Promotion } & $M$ & 3.65 & 18.27 & 1.87 & 2.81 & 1.92 & 1.58 & 3.40 \\
\hline & $S D$ & 0.70 & 6.16 & 1.06 & 1.01 & 1.68 & 0.84 & 1.19 \\
\hline \multirow[t]{2}{*}{ Prevention } & M & 3.36 & 18.89 & 1.87 & 2.89 & 2.17 & 1.63 & 3.24 \\
\hline & $S D$ & 0.76 & 6.51 & 0.78 & 0.95 & 1.73 & 0.71 & 1.10 \\
\hline \multirow{2}{*}{$\begin{array}{l}\text { Yoked- } \\
\text { Control }\end{array}$} & $M$ & 3.71 & 18.28 & 1.74 & 3.12 & 1.96 & 1.55 & 3.58 \\
\hline & $S D$ & 0.66 & 5.75 & 0.80 & 0.96 & 1.62 & 0.66 & 0.95 \\
\hline
\end{tabular}

Note. $\mathrm{RT}=$ repetitive thought. $\mathrm{T} 2=$ post-writing assessment of affect. $\mathrm{T} 3=$ post-quiet period assessment of affect. $t p<.10 ;{ }^{*} p<.05 ;{ }^{* *} p<.01 ;{ }^{* * *} p<.001$.

chronic promotion failure. Figure 1 summarizes the mean changes in dejection as a function of priming condition (within-subject) and level of chronic promotion failure (between-subjects). Participants at moderate (at the mean) to high (1 SD above the mean) levels of chronic promotion failure experienced a significant increase in dejection when writing about past failures to live up to both promotion and prevention goals, but there was no significant increase in dejection in the yoked-control condition. The observed increase in dejection in the prevention condition was unexpected. Also of note, individuals who were low in chronic promotion failure did not report changes in dejection in any of the conditions ( $p s>.05)$. 


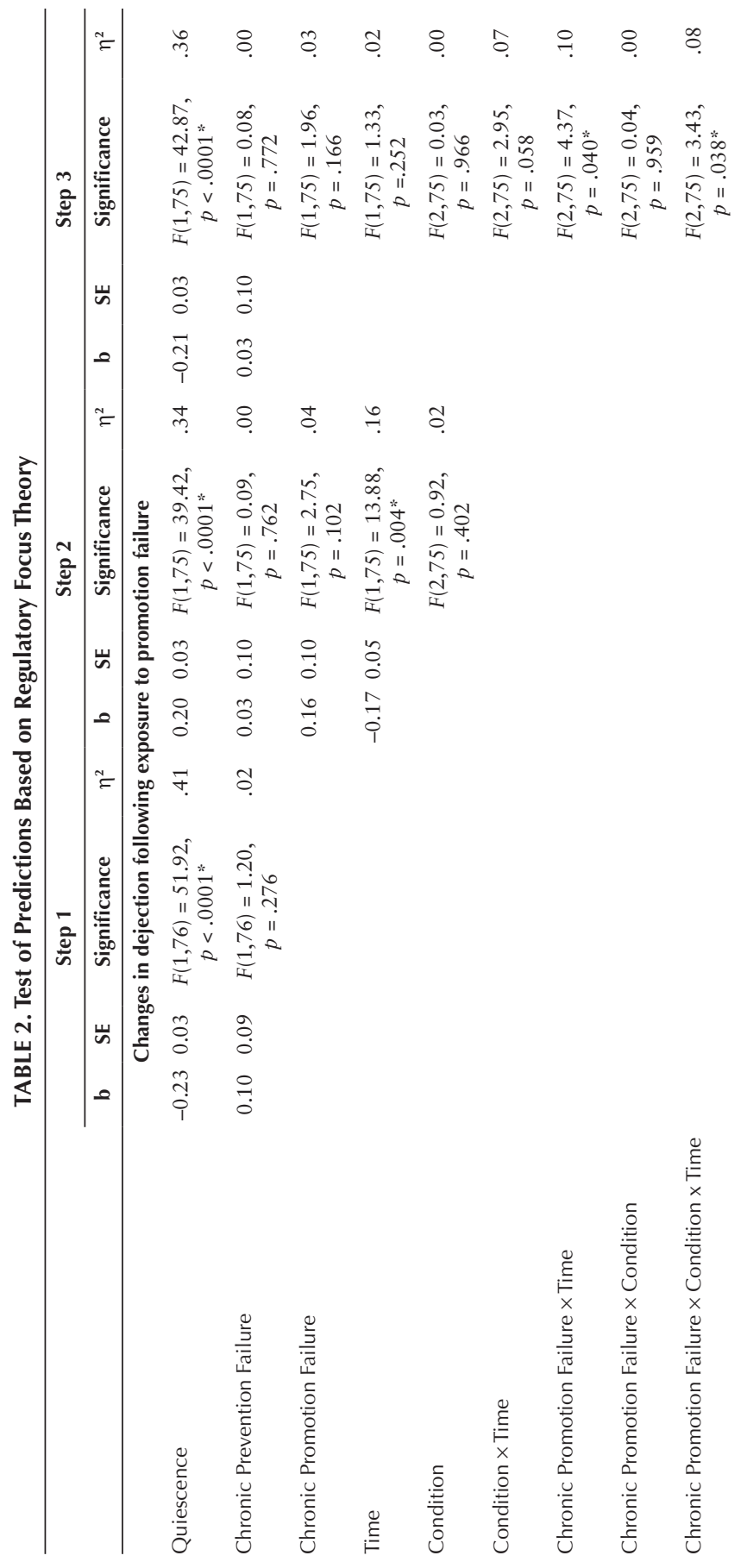




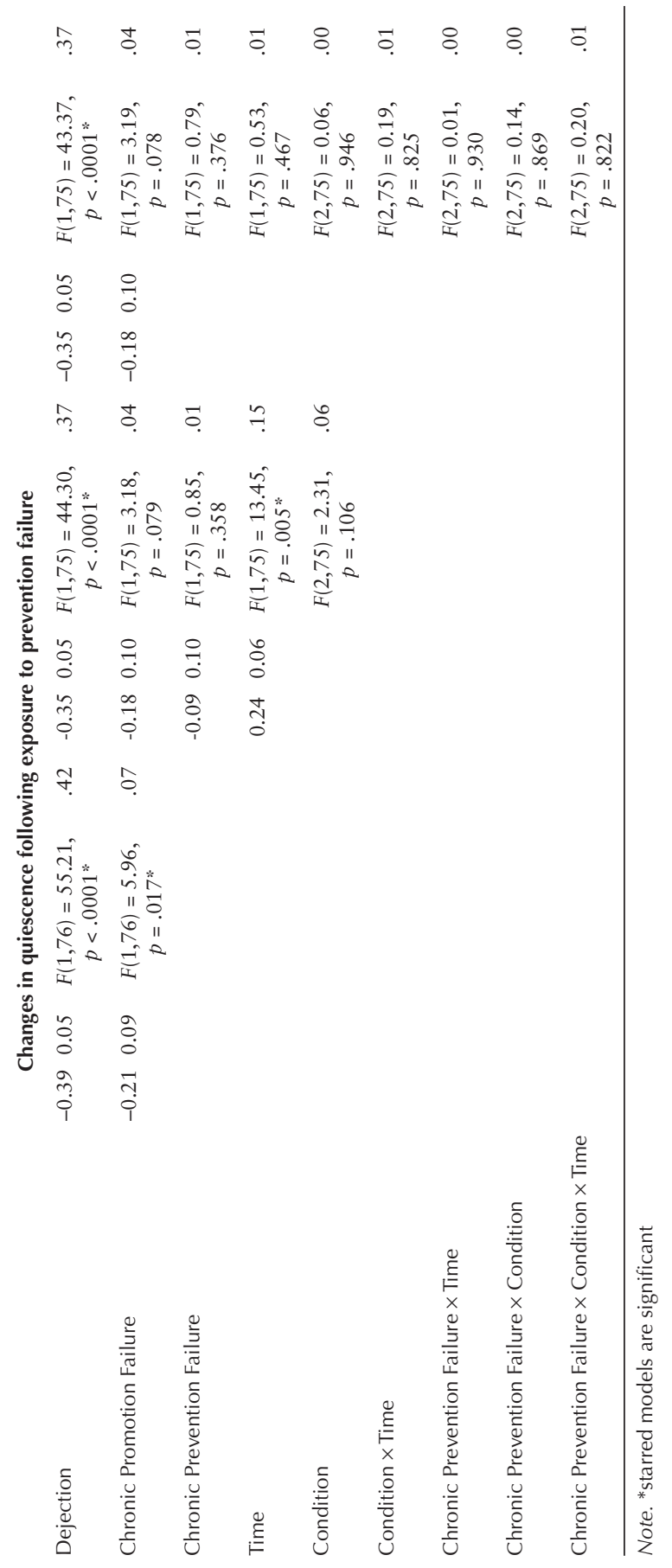




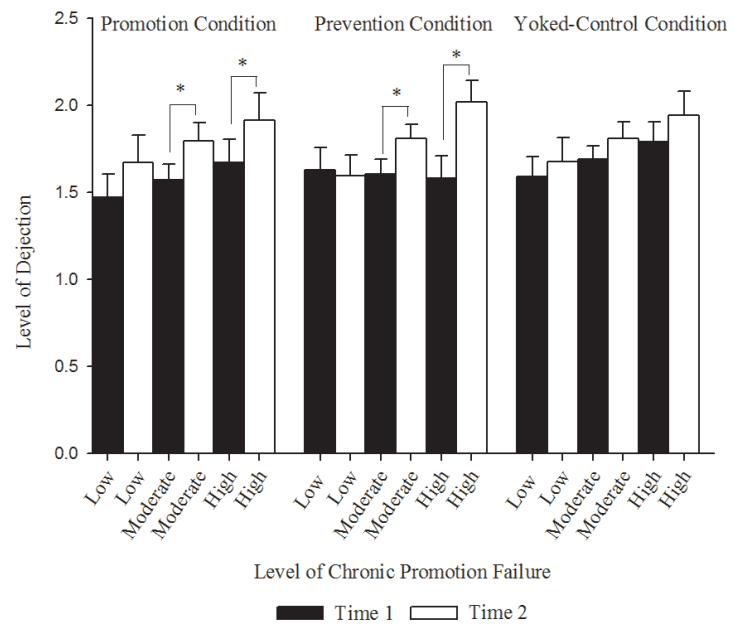

FIGURE 1. Changes in dejection as a function of experimental condition and level of chronic promotion failure controlling for quiescence and chronic prevention failure.

\section{Changes in Quiescence Following Exposure to Prevention Failure}

We also tested the prediction that priming of past failures to attain prevention goals would be uniquely associated with decreases in quiescence for individuals with chronic prevention goal failure. We conducted an analysis parallel to the one reported above. Because the predicted 3-way interaction chronic prevention failure $\times$ condition $\times$ time interaction and all of the 2-way interactions were not significant in step 3 (see Table 1), the main effects in step 2 were interpreted.

After controlling for dejection, $b=-0.35, S E=0.05, F(1,75)=44.30$, $p<.0001, \eta^{2}=.37$, and chronic promotion failure, $b=-0.18, S E=0.10$, $F(1,75)=3.18, p=.079, \eta^{2}=.04$, which demonstrated the expected effects, there was no main effects of chronic prevention failure, $b=$ $-0.09, S E=0.10, F(1,75)=0.85, p=.358, \eta^{2}=.01$, or condition, $F(2,75)$ $=2.31, p=.106, \eta^{2}=.06$, on quiescence. However, there was a main effect of time, $b=0.24, S E=0.06, F(1,75)=13.45, p=.005, \eta^{2}=.15$, indicating a decrease in quiescence from T1 $(M=3.26, S E=0.07)$ to $\mathrm{T} 2(M=3.02, S E=0.07)$ across all conditions. These results indicate that regardless of condition or level of chronic prevention failure all participants experienced a decrease in quiescence. 


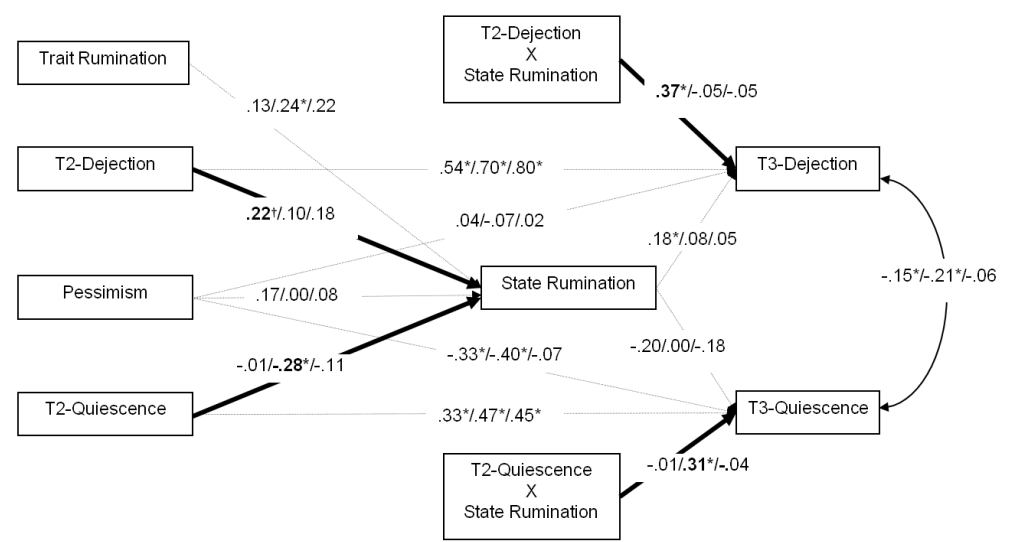

Promotion Condition: $x^{2}=3.94, d f=4, p=.414 ; \mathrm{CFI}=1.00 ;$ RMSEA $=0.00$ Prevention Condition: $X^{2}=20.65, d f=5, p=.001 ; \mathrm{CFI}=0.88$; RMSEA $=0.24$ Yoked-Control Condition: $X^{2}=11.45, d f=5, p=.043 ; C F I=0.93 ;$ RMSEA $=0.16$ Note. ${ }^{*} p<.05$, State Rumination = rumination during the meditation period; bolded State Rumination: $R^{2}=.16 / .20 / .12$ T3-Dejection: $R^{2}=.76 / .49 / .59$ lines denote predicted results.

FIGURE 2. Path analyses examining the unique predictors and affective consequences of engaging in state rumination within each experimental condition (promotion/ prevention/yoked-control, respectively).

\section{DIFFERENCES IN STATE RUMINATION ACROSS CONDITIONS}

We tested the hypothesis that writing about promotion and prevention goal failure would lead to a greater incidence of state rumination when compared to writing about yoked-control failure. We began by testing for a main effect of priming condition. However, levels of rumination reported after writing about promotion, prevention, and yoked-control failures did not differ significantly, $F(2,77)=0.40, p=.675, \eta^{2}=.01$; see Table 1 for descriptive statistics.

\section{Predictors of State Rumination and Affect Changes from Post-Writing to Post-Meditation.}

We then conducted three path analyses to test theory-based models of the functional associations among chronic goal failure, state rumination, and distress. One path analysis for each condition tested for potential predictors of state rumination following exposure to goal failure (i.e., during the quiet period) and the effect of state rumination on changes in negative affective states (i.e., from T2 to T3). The prediction of state rumination was included a priori after 


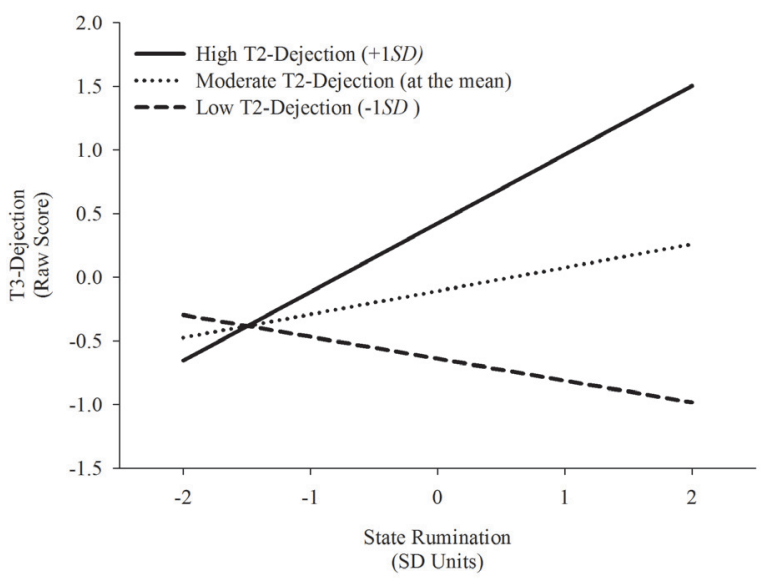

FIGURE 3. Post-promotion goal failure dejection (T2) moderates the effect of state rumination on post-mediation period dejection (T3) evaluated 5 minutes later.

observing that the yoked-control condition proved to be an active condition (i.e., induced decreases in quiescence). In each of the path analyses we controlled for individual differences in trait rumination and pessimism to more clearly examine unique predictors of state rumination following the experimental manipulation.

Promotion Condition. Our hypothesized model had excellent fit for the promotion condition (see Figure 2). Participants with higher T2Dejection engaged in marginally more state rumination $(\beta=0.22$, $S E=0.13, p=.083)$. T2-quiescence, trait rumination, and pessimism were not significant predictors of state rumination (all $p \mathrm{~s}>.05$ ). The direct effects of T2-dejection and rumination on T3-dejection were qualified by a T2-dejection $\times$ rumination interaction $(\beta=0.37$, $S E=0.08, p<.0001)$. As shown in Figure 3, probing of the interaction indicated that participants who experienced high levels of T2-Dejection $(b=0.54, S E=0.11, p<.0001)$ or moderate levels $(b=$ $0.18, \mathrm{SE}=0.08, p=.021)$ of T2-Dejection reported higher levels of T3-Dejection as a function of the extent to which they engaged in state rumination; in contrast, state rumination was not associated with T3-Dejection for participants who experienced low levels $(b=$ $-0.17, S E=0.10, p=.110$ ) of T2-Dejection. The two-way interaction between T2-quiescence and state rumination was not a significant predictor of T3-quiescence $(p>.05)$. 


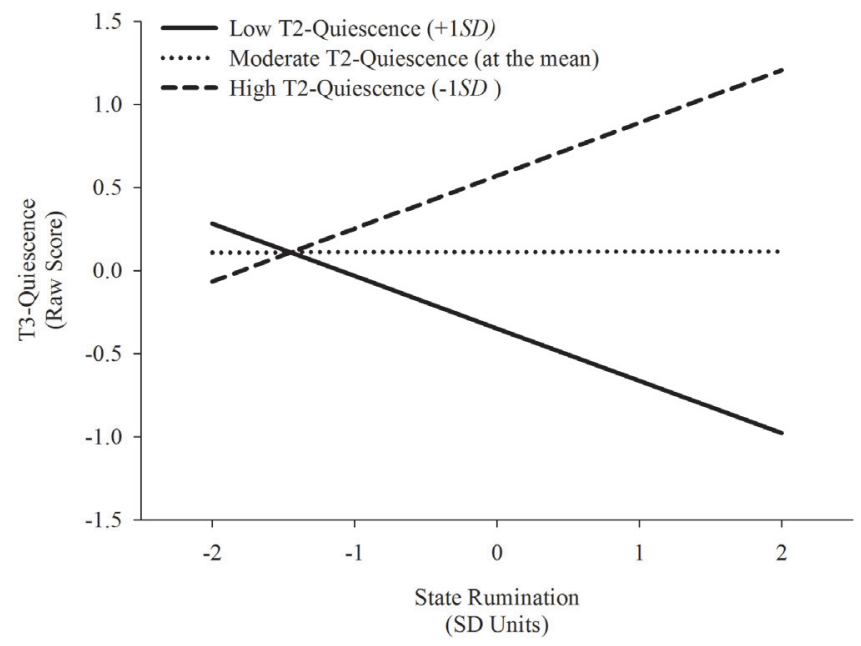

FIGURE 4. Post-prevention goal failure quiescence (T2) moderates the effect of state rumination on post-mediation period quiescence (T3) evaluated 5 minutes later.

Prevention Condition. Our hypothesized model had poor fit for the prevention condition (see Figure 2). Participants with lower T2Quiescence $(\beta=-0.28, S E=0.11, p=.009)$ and high levels of trait rumination ( $\beta=0.24, S E=0.11, p=.037)$ engaged in significantly more state rumination. T2-dejection and pessimism were not significant predictors of state rumination ( $p s>.05$ ). The direct effects of T2-quiescence and state rumination on T3-quiescence were qualified by a T2-quiescence $\times$ state rumination interaction $(\beta=0.31, S E$ $=0.09, p=.001)$. As shown in Figure 4 , the interaction indicated that participants who experienced low levels of T2-Quiescence $(b=$ $-0.32, S E=0.15, p=.039)$ reported lower levels of T3-Quiescence as a function of the extent to which they engaged in state rumination. In contrast, state rumination was not associated with T3-Quiescence for participants who experienced moderate $(b=0.00, S E=0.11, p=$ $.989)$ or high levels $(b=0.32, S E=0.17, p=.072)$ of T2-Quiescence. The two-way interaction between T2-Dejection and state rumination was not a significant predictor of T3-dejection.

Yoked-Control Condition. As shown in Figure 1, as expected, our theory-based model did not fit the yoked-control data well. Trait rumination, trait pessimism, T2-dejection, and T2-quiescence were not significant predictors of state rumination during the quiet pe- 
riod ( $p s>.05)$. Furthermore, as expected, the only significant predictors of T3-dejection and T3-quiescence were T2-dejection and T2-quiescence, respectively (all other $p \mathrm{~s}>.05$ ).

\section{DISCUSSION}

The primary study aim was to examine rumination as a process that may increase acute distress following goal failure, which could lead to the more prolonged and intense emotional distress that is characteristic of mood and anxiety disorders (Strauman et al., 2007, pp. 859-861). Therefore, we primed participants' past failures to attain promotion or prevention goals and examined the predictors and emotional consequences of engaging in rumination. Consistent with theory and past research (Strauman, 1992), we observed that exposing individuals who perceived themselves as chronically failing to attain promotion goals to their promotion goal failures induces acute dejection. Unexpectedly, those participants also experienced increased dejection following exposure to their prevention goal failures. It is possible that for the individuals with high levels of chronic promotion goal failure, priming them with prevention failures activated highly accessible memories related to past promotion failures as well (Shah, 2005). That activation could have resulted in the observed increase in dejection in the prevention condition. Participants also experienced a decrease in quiescence after exposure to all types of goal failure regardless of their level of chronic prevention goal failure. Thus our prevention condition failed to induce a greater decrease in quiescence relative to the other conditions. This may have occurred because the prevention priming manipulation induced the recall of situations associated with anger rather than anxiety.

We did not observe a main effect of goal failure priming on the initiation of state rumination; that is, writing about past failures to meet promotion or prevention goals did not produce higher levels of state rumination compared to the yoked-control condition. This may have occurred because many participants likely found ways during the task in the promotion and prevention conditions to reduce their perceived self-discrepancy or to disengage from the target goal. Consistent with our integrative perspective on selfregulation and rumination, being able to effectively self-regulate in this manner would reduce, rather than increase, their levels of 
state rumination and distress (Carver \& Scheier, 1998; Martin \& Tesser, 1996). It is also likely that thinking about past promotion and prevention goal failures is a less potent inducer of rumination than acute experiences of goal failure (e.g., Moberly \& Watkins, 2010).

However, we did find that inducing participants to write about promotion (advancement and growth) and prevention (safety and security) goal failures prompted rumination. Indeed, participants who experienced greater dejection following exposure to promotion goal failures or experienced less quiescence following exposure to prevention goal failures engaged in more rumination. Given that the level of dejection or quiescence experienced following acute goal priming offered a reliable assessment of the level of promotion or prevention goal failure experienced during the experiment (Higgins, 1987), our results also provide some support for the assertion that failing to attain specific types of personal goals leads to rumination.

Overall, the present findings are consistent with previous studies which indicate that the perception of failure to attain important, personally relevant goals can lead to increases in rumination (e.g., Lavallee \& Campbell, 1995; Moberly \& Watkins, 2010). As such, our results provide further support for self-regulatory explanations of rumination (e.g., Martin \& Tesser, 1996; Watkins, 2008). Further, our results suggest that rumination combined with preexisting tendencies to experience negative emotions evoked by the recognition of goal failures leads to intensified negative affect over a five-minute period. Consistent with our predictions, individuals who experienced high levels of dejection in the promotion failure condition had the strongest association between post-meditation dejection and rumination. Similarly, individuals who experienced low levels of quiescence in the prevention failure condition had the strongest association between post-meditation quiescence and rumination. Those findings are consistent with previous research findings that there is a reciprocal intensifying relation wherein negative affect prospectively predicts increased state rumination and increased state rumination predicts increased negative affect (Moberly \& Watkins, 2008), and further, suggest there is a feedforward mechanism that could transform acute distress following goal failure into chronic distress.

Our results are also consistent with studies on depressive rumination which demonstrate existing negative affect is necessary for depressive rumination to amplify mood states (e.g., Nolen-Hoeksema 
\& Morrow, 1993). Our findings extend this work by identifying goal failure as a frequent, ubiquitous source of negative emotion that triggers rumination and by demonstrating that naturally occurring rumination amplifies this existing emotional state. Our findings are also consistent with our previous work demonstrating that dispositional tendencies to ruminate combined with chronic perceived promotion goal failure are associated with increased depressive symptoms (Jones et al., 2009; Papadakis et al., 2006).

Some limitations of the current study warrant discussion. First, our sample of graduate and professional students was more highly educated than the general population. Also, in our participants' social context, cues for success and failure in attaining important personal goals are common and carry considerable motivational significance. However, graduate and professional students face many of the same stressors as adults in general (e.g., navigating marital responsibilities and financial difficulties; Hyun, Quinn, Madon, \& Lustig, 2006), suggesting that our findings may have some generalizability. Second, our data cannot allow us to say definitely that the participants were ruminating about promotion or prevention goals during the quiet period; they could have been ruminating about something else. Third, the sample was predominately female, which prevented an examination of gender differences. Moreover, given that women ruminate more than men (Nolen-Hoeksema, Morrow, \& Fredrickson, 1993), it is possible that smaller effects would be observed in more gender balanced samples. Fourth, we generated a measure of state rumination because at the time there was none. While our measure has excellent face validity and good convergent validity, its full psychometric properties need to be assessed. Fifth, affect and state rumination were not assessed continuously during the experiment. It is probable that the emotional peaks occurred during the writing task and were not captured fully at the end of the 15-minute task, which may have resulted in somewhat attenuated measurements of the magnitude of the emotions. Similarly, we may have missed the peak in rumination, which likely occurred during the writing task and quiet period. Future investigations would benefit from continuous measures of affect and rumination using biological indices (Jones, Siegle, Muelly, Haggerty, \& Ghinassi, 2010).

In summary, our results suggest that emotional responses to promotion and prevention goal failure can lead to rumination, which prolongs the salience of perceived failure to make progress toward personal goals, thereby intensifying negative emotional states as- 
sociated with failure. Conceptualizing rumination as resulting from difficulties in self-regulation may have profound implications for treating depression among individuals who ruminate, which extends the time to recovery (Jones, Siegle, \& Thase, 2008). For example, clinicians may want to help patients to disengage from maladaptive goals. Further research is needed to determine what self-regulatory interventions are most effective and for whom these interventions warranted.

\section{REFERENCES}

Abela, J.R.Z., \& Hankin, B. L. (2011). Rumination as a vulnerability factor to depression during the transition from early to middle adolescence: A multiwave longitudinal study. Journal of Abnormal Psychology, 120, 259.

Beck, A. T., Ward, C., Mendelson, M., Mock, J., \& Erbaugh, J. (1961). An inventory for measuring depression. Archives of General Psychiatry, 4, 561-571.

Boldero, J. M., Moretti, M. M., Bell, R. C., \& Francis, J. J. (2005). Self-discrepancies and negative affect: A primer on when to look for specificity, and how to find it. Australian Journal of Psychology, 57, 139-147.

Brunstein, J. C., \& Gollwitzer, P. M. (1996). Effects of failure on subsequent performance: The importance of self-defining goals. Journal of Personality and Social Psychology, 70, 395-407.

Carver, C. S., \& Scheier, M. F. (1998). On the self-regulation of behavior. New York: Cambridge University Press.

Chang, E. C., Maydeu-Olivares, A., \& D'Zurilla, T. J. (1997). Optimism and pessimism as partially independent constructs: Relationship to positive and negative affectivity and psychological well-being. Personality and Individual Differences, 23, 433-440.

Ehring, T., Zetsche, U., Weidacker, K., Wahl, K., Schönfeld, S., \& Ehlers, A. (2011). The perseverative thinking questionnaire (PTQ): Validation of a content-independent measure of repetitive negative thinking. Journal of Behavior Therapy and Experimental Psychiatry, 42, 225-232.

Feldman, G., Greeson, J., \& Senville, J. (2010). Differential effects of mindful breathing, progressive muscle relaxation, and loving-kindness meditation on decentering and negative reactions to repetitive thoughts. Behaviour Research and Therapy, 48, 1002-1011.

Hardin, E. E., \& Lakin, J. L. (2009). The integrated self-discrepancy index: A reliable and valid measure of self-discrepancies. Journal of Personality Assessment, 91, 245-253.

Hardin, E. E., \& Leong, F.T.L. (2005). Optimism and pessimism as mediators of the relations between self-discrepancies and distress among Asian and European Americans. Journal of Counseling Psychology, 52, 25-35.

Higgins, E. T. (1987). Self-discrepancy: A theory relating self and affect. Psychological Review, 94, 319-340.

Higgins, E. T. (1997). Beyond pleasure and pain. American Psychologist, 52, 12801300 . 
Hyun, J. K., Quinn, B. C., Madon, T., \& Lustig, S. (2006). Graduate student mental health: Needs assessment and utilization of counseling services. Journal of College Student Development, 47, 247-266.

Jain, S., Shapiro, S. L., Swanick, S., Roesch, S. C., Mills, P. J., Bell, I., \& Schwartz, G.E.R. (2007). A randomized controlled trial of mindfulness meditation versus relaxation training: Effects on distress, positive states of mind, rumination, and distraction. Annals of Behavioral Medicine, 33, 11-21.

Jones, N. P., Papadakis, A. A., Hogan, C. M., \& Strauman, T. J. (2009). Over and over again: Rumination, reflection, promotion goal failure, and their interactive effects on depressive symptoms. Behavior Research and Therapy, 47, 254-259.

Jones, N. P., Siegle, G. J., Muelly, E. R., Haggerty, A., \& Ghinassi, F. (2010). Poor performance on cognitive tasks in depression: Doing too much or not enough? Cognitive, Affective, and Behavioral Neuroscience, 10, 129-140.

Jones, N. P., Siegle, G. J., \& Thase, M. E. (2008). Effects of rumination and initial severity on remission to cognitive therapy for depression. Cognitive Therapy and Research, 32, 591-604.

Landis, R. S., Beal, D. J., \& Tesluk, P. E. (2000). A comparison of approaches to forming composite measures in structural equation models. Organizational Research Methods, 3, 186-207.

Lavallee, L. F., \& Campbell, J. D. (1995). Impact of personal goals on self-regulation processes elicited by daily negative events. Journal of Personality and Social Psychology, 69, 341-352.

Martin, L. L., \& Tesser, A. (1996). Some ruminative thoughts. In R. S. Wyer, Jr. (Ed.), Ruminative thoughts (pp. 1-47). Hillsdale, NJ: Lawrence Erlbaum Associates, Inc.

Martin, L. L., \& Tesser, A. (2006). Extending the goal progress theory of rumination: Goal reevaluation and growth. In L. J. Sanna \& E. C. Ho (Eds.), Judgments over time: The interplay of thoughts, feelings, and behaviors. New York: Oxford University Press.

Moberly, N. J., \& Watkins, E. (2008). Ruminative self-focus and negative affect: An experience sampling study. Journal of Abnormal Psychology, 117, 314-323.

Moberly, N. J., \& Watkins, E. (2010). Negative affect and ruminative self-focus during everyday goal pursuit. Cognition \& Emotion, 24, 729-739.

Nolen-Hoeksema, S., \& Morrow, J. (1991). A prospective study of depression and posttraumatic stress symptoms after a natural disaster: The 1989 Loma Prieta earthquake. Journal of Personality and Social Psychology, 61, 115-121.

Nolen-Hoeksema, S., \& Morrow, J. (1993). Effects of rumination and distraction on naturally occurring depressed mood. Cognition \& Emotion, 7, 561-570.

Nolen-Hoeksema, S., Morrow, J., \& Fredrickson, B. L. (1993). Response styles and the duration of episodes of depressed mood. Journal of Abnormal Psychology, 102, 20-28.

Papadakis, A. A., Prince, R. P., Jones, N. P., \& Strauman, T. J. (2006). Self-regulation, rumination, and vulnerability to depression in adolescent girls. Development and Psychopathology, 18, 815-829.

Pennebaker, J. W., Francis, M. E., \& Booth, R. J. (2001). Linguistic inquiry and word count: LIWC 2001. Manwah, NJ: Lawrence Erlbaum.

Segerstrom, S. C., Tsao, J. C., Alden, L. E., \& Craske, M. G. (2000). Worry and rumination: Repetitive thought as a concomitant and predictor of negative mood. Cognitive Therapy and Research, 24, 671-688. 
Shadish, W. R., Cook, T. D., \& Campbell, D. T. (2002). Experimental quasi-experimental designs for generalized causal inference. Boston: Houghton Mifflin Company.

Shah, J. Y. (2005). The automatic pursuit and management of goals. Current Directions in Psychological Science, 14, 10-13.

Siegle, G. J., Moore, P. M., \& Thase, M. E. (2004). Rumination: One construct, many features in healthy individuals, depressed individuals, and individuals with lupus. Cognitive Therapy and Research, 28, 645-668.

Strauman, T. J. (1992). Self-guides, autobiographical memory, and anxiety and dysphoria: Toward a cognitive model of vulnerability to emotional distress. Journal of Abnormal Psychology, 101, 87-95.

Strauman, T. J. (2002). Self-regulation and depression. Self and Identity, 1, 151-157.

Strauman, T. J., Costanzo, P. R., Jones, N. P., McLean, A. N., \& Eddington, K. M. (2007). Contributions of social psychology to clinical psychology: Three views of a research frontier. In E. T. Higgins \& A. W. Kruglanski (Eds.), Social psychology: Handbook of basic principles (2nd Ed., pp. 850-868). New York: Guilford.

Thomsen, D. K. (2006). The association between rumination and negative affect: A review. Cognition \& Emotion, 20, 1216-1235.

Thomsen, D. K., Jørgensen, M., Mehlsen, M. Y., \& Zachariae, R. (2004). The influence of rumination and defensiveness on negative affect in response to experimental stress. Scandinavian Journal of Psychology, 45, 253-258.

Trapnell, P. D., \& Campbell, J. D. (1999). Private self-consciousness and the five-factor model of personality: Distinguishing rumination from reflection. Journal of Personality and Social Psychology, 76, 284-304.

Walter, O., Becker, J., Bjorner, J., Fliege, H., Klapp, B., \& Rose, M. (2007). Development and evaluation of a computer adaptive test for 'anxiety' (Anxiety-CAT). Quality of Life Research, 16, 143-155.

Watkins, E. (2008). Constructive and unconstructive repetitive thought. Psychological Bulletin, 134, 163-206.

Watson, D., \& Clark, L. A. (1990). Preliminary manual for the positive and negative affect schedule (Expanded form). Southern Methodist University, Dallas TX.

Watson, D., \& Clark, L. (1994). The PANAS-X: Manual for the positive and negative affect schedule-expanded form. Iowa City: University of Iowa.

Wegner, D. M., \& Zanakos, S. (1994). Chronic thought suppression. Journal of Personality, 62, 615-640. 